\title{
Minocycline for Controlling Neuropathic Pain: A Systematic Narrative Review of Studies in Humans
}

This article was published in the following Dove Press journal: Journal of Pain Research

\author{
Dong Ah Shin' \\ Tae Uk Kim (D) ${ }^{2}$ \\ Min Cheol Chang ${ }^{3}$ \\ 'Department of Neurosurgery, Yonsei \\ University, College of Medicine, Seoul, \\ Republic of Korea; ${ }^{2}$ Department of \\ Physical Medicine and Rehabilitation, \\ College of Medicine, Dankook University, \\ Cheonan, Republic of Korea; \\ ${ }^{3}$ Department of Physical Medicine and \\ Rehabilitation, College of Medicine, \\ Yeungnam University, Taegu, Republic of \\ Korea
}

Objective: Minocycline is known to reduce microglial activation, suggesting that it may reduce neuropathic pain. We reviewed studies in humans that evaluated the effectiveness of minocycline in alleviating neuropathic pain.

Methods: We searched the PubMed, Embase, Cochrane library, and SCOPUS databases for papers published before January 06,2021 , using the search words minocycline and pain. The inclusion criteria for the selection of articles were (1) minocycline administered to humans and (2) minocycline administered to control neuropathic pain.

Results: The primary literature search yielded 2299 relevant papers. Based on the assessment of the titles, abstracts, and full-text, nine publications were selected for this review. Only four of the nine studies showed a positive pain-reducing outcome after minocycline administration. Two of the three studies on chemotherapy-induced neuropathic pain showed a positive pain-reducing effect. Minocycline was effective in controlling pain from diabetic and leprotic neuropathies. However, minocycline was not effective in controlling lumbar radicular pain and pain resolution after carpal tunnel release.

Conclusion: Our review provides evidence that minocycline may have some potential for reducing neuropathic pain. Further high-quality studies need to be conducted to validate this potential.

Keywords: minocycline, microglia, neuropathic pain, pain, review

\section{Introduction}

Chronic pain is characterized by enhanced sensory neurotransmission that increases sensitivity to noxious stimuli and the perception of non-noxious stimuli as pain. ${ }^{1}$ Neuropathic pain is one of the most common and debilitating chronic pain conditions that considerably deteriorates patients' activities of daily living and quality of life. ${ }^{2}$ Neuropathic pain is caused by several diseases, including metabolic (eg, diabetic neuropathy), autoimmune (eg, multiple sclerosis), and vascular (eg, stroke and spinal cord infarct) diseases and infection (eg, postherpetic neuralgia), trauma, and cancer. The mechanism underlying neuropathic pain is not clearly understood; however, several likely mechanisms have been suggested, including sensitization of the central and peripheral nervous systems, deafferentation, neurogenic inflammation, and wind-up. ${ }^{3}$ In clinical practice, several therapeutic methods such as medications, modalities, and procedures are being applied. ${ }^{4,5}$ However, many cases of chronic pain are refractory to these treatments. Therefore, researchers are attempting to develop novel treatments for alleviating chronic pain.
Correspondence: Min Cheol Chang Department of Physical Medicine and Rehabilitation, College of Medicine,

Yeungnam University, 317-I,

Daemyungdong, Namku, Taegu 705-717,

Republic of Korea

Tel +82-53-620-4682

Email wheel633@ynu.ac.kr
Journal of Pain Research 2021:14 139-145 
Regarding medications for reducing neuropathic pain, anticonvulsants (gabapentin or pregabalin), tricyclic antidepressants, and opioids are usually prescribed. ${ }^{1}$ These drugs primarily target neurons including axons and dendrites. ${ }^{6}$ Various adverse effects related to the restraint of neuronal activity, such as somnolence or dizziness, are unavoidable. Additionally, these drugs are not sufficient to control neuropathic pain.

Recently, glial cells, especially microglia, have been considered to play an essential role in central sensitization, one of the main mechanisms for the development and persistence of neuropathic pain. ${ }^{7}$ When the nerve is injured, microglia in the dorsal horn are activated and enhance the release of pro-nociceptive neurotransmitters such as glutamate, cytokines, and chemokines. ${ }^{8}$ This process enhances neuron-glia communication and results in the sensation of persistent pain despite the absence of continuous noxious stimuli to the tissue. Once microglia are activated, the process related to chronic pain continues, and it is difficult to break this process. ${ }^{9}$ With the recognition of microglia as prime modulators of progress to chronic pain, considerable effort has been spent in developing drugs to inhibit microglial activation.

Minocycline is a second-generation, semi-synthetic tetracycline that is used as a broad-spectrum antibiotic against a wide range of microorganisms. ${ }^{10}$ It is also known to have several anti-inflammatory properties, including the reduction in microglial activation, inhibition of T-lymphocytes, suppression of phospholipase A2 activation, and decrease in interleukin (IL)- 6 and IL-8. ${ }^{11-13}$ Minocycline is lipophilic and can penetrate the bloodbrain barrier and act on the central nervous system. ${ }^{14}$ Several animal studies have shown that minocycline attenuates neuropathic pain after injury of peripheral and central nerves via microglial inhibition. ${ }^{11-13,15}$ Minocycline is known to inhibit the expression of tolllike receptor 4 , which is a crucial receptor for microgliamediated neuroinflammation. ${ }^{16}$ Consequently, inhibition of microglial cell activity inhibits the production of inflammatory cytokines and the expression of brainderived neurotrophic factor. ${ }^{15,17,18}$ Recently, the effect of minocycline on neuropathic pain has been evaluated in patients with various types of neuropathic pain. In addition, minocycline has neuroprotective properties via antioxidant activity. ${ }^{19,20}$ This is related to the ability to chelate mitochondrial iron, which catalyzes toxic hydroxyl radical formation. Accordingly, minocycline attenuates neuronal cell death.
In the current study, we systematically reviewed previous studies that evaluated the effectiveness of minocycline in alleviating neuropathic pain in humans.

\section{Methods}

The PubMed, Embase, Cochrane library, and SCOPUS databases were searched for articles published before January 06, 2021 using the search terms minocycline AND pain. Articles related to minocycline administered to humans to control neuropathic pain were selected. Research on all types of neuropathic pain was included in our review. Animal studies and review articles were excluded. In addition, we only included articles published in English.

\section{Results}

The primary literature search yielded a total of 3243 potentially relevant papers, among which 944 duplicate articles were removed (Figure 1). After screening for eligibility, based on a review of the title and abstract, 20 articles were identified for full-text reading. After a detailed assessment, 11 articles were excluded. Accordingly, nine publications were selected for this review. $^{21-29}$ In these selected studies, minocycline was administered in a total of 232 cases. Among the included studies (Table 1), the effectiveness of minocycline in treating chemotherapy-induced neuropathic pain was evaluated in three studies ${ }^{24,28,29}$ and lumbar radicular pain in two studies. ${ }^{22,27}$ Its effectiveness was also evaluated in diabetic neuropathy, ${ }^{26}$ leprosy, ${ }^{23}$ and carpal tunnel syndrome. ${ }^{21}$ One study was not classified according to any disease indication. ${ }^{25}$ Seven studies were randomized controlled trials (RCTs), and the other two were prospective observational studies. In all the included studies, minocycline was administered orally.

Among the studies evaluating the pain-reducing effects on chemotherapy-induced neuropathic pain, two studies showed a positive effect, ${ }^{24,29}$ and the other ${ }^{28}$ presented negative results. Pachman et $\mathrm{al}^{24}$ performed an RCT involving 45 patients with breast cancer receiving weekly paclitaxel chemotherapy. Twenty-two patients received minocycline $100 \mathrm{mg}$ twice daily until 12 weeks of chemotherapy were completed, and 23 patients received a placebo. The degree of neuropathic pain was evaluated by asking patients to maintain a daily symptom questionnaire during chemotherapy comprising 10 items regarding pain symptoms and the use of pain medications. The patients in the minocycline group reported less pain and 


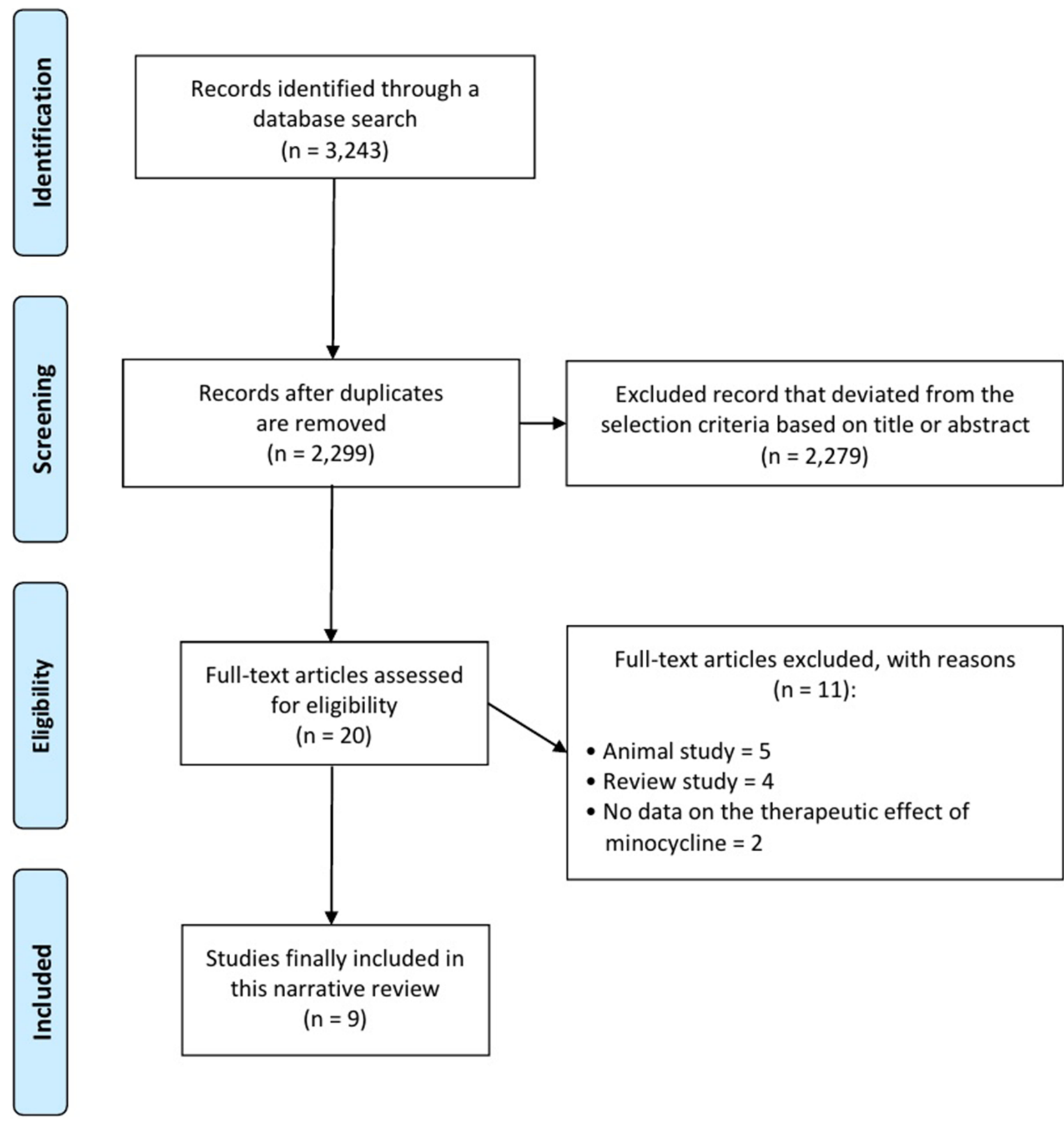

Figure I Flow chart showing the study design and selection of eligible studies.

less use of opioid pain medication than the placebo group. Wang et $\mathrm{al}^{29}$ evaluated minocycline for controlling chemoradiation-related symptoms. They recruited 40 patients with non-small cell lung cancer who were scheduled to receive chemoradiation treatment. Patients were randomly assigned to either the minocycline group (100 mg twice daily) (19 patients) or placebo group (21 patients) over 6-7 weeks of chemoradiation therapy. Pain, fatigue, and shortness of breath were significantly reduced in the minocycline group. However, another study performed by the same research group (Wang et al) ${ }^{28}$ reported no beneficial effect of minocycline. They recruited 66 patients with locally advanced or metastatic colorectal cancer who were scheduled for oxaliplatin-based chemotherapy. Patients were randomly allocated to receive either minocycline (100 mg twice daily) (32 patients) or placebo (34 
Table I Summary of the Included Studies

\begin{tabular}{|c|c|c|c|c|c|c|c|c|}
\hline \# & $\begin{array}{l}\text { First } \\
\text { Authors }\end{array}$ & Year & Disease & $\begin{array}{l}\text { Study } \\
\text { Design }\end{array}$ & $\begin{array}{l}\text { No. of } \\
\text { Patients } \\
\text { (Minocycline: } \\
\text { Placebo) }\end{array}$ & $\begin{array}{l}\text { Minocycline } \\
\text { Dose }\end{array}$ & Duration & Results \\
\hline I & Pachman $^{24}$ & 2017 & $\mathrm{CIN}$ & $\mathrm{RCT}$ & $45(22: 23)$ & $\begin{array}{l}100 \text { mg twice } \\
\text { daily }\end{array}$ & 12 weeks & $\begin{array}{l}\text { During chemotherapy, less pain (10- } \\
\text { item questionnaire) and less use of } \\
\text { opioids in the minocycline group. }\end{array}$ \\
\hline 2 & Wang ${ }^{28}$ & 2019 & $\mathrm{CIN}$ & RCT & $66(32: 34)$ & $\begin{array}{l}100 \text { mg twice } \\
\text { daily }\end{array}$ & 4 months & $\begin{array}{l}\text { On MDASI, no significant } \\
\text { improvement in fatigue and } \\
\text { neuropathic pain }\end{array}$ \\
\hline 3 & Wang $^{29}$ & 2020 & $\mathrm{CIN}$ & $\mathrm{RCT}$ & $40(19: 21)$ & $\begin{array}{l}100 \mathrm{mg} \text { twice } \\
\text { daily }\end{array}$ & $\begin{array}{l}6-7 \\
\text { weeks }\end{array}$ & $\begin{array}{l}\text { On MDASI, pain, fatigue, and } \\
\text { shortness of breath were } \\
\text { significantly reduced in the } \\
\text { minocycline group }\end{array}$ \\
\hline 4 & Martinez ${ }^{22}$ & 2013 & $\begin{array}{l}\text { Lumbar } \\
\text { radicular } \\
\text { pain }\end{array}$ & RCT & $85(43: 42)$ & $\begin{array}{l}100 \text { mg twice } \\
\text { daily }\end{array}$ & 8 days & $\begin{array}{l}\text { On NRS, at rest, } 2.3 \text { reduction in } \\
\text { score in the minocycline group vs } \\
\text { I.7 reduction in the placebo group. } \\
\text { On movement, } 3.4 \text { reduction in } \\
\text { score in the minocycline group vs } \\
2.5 \text { reduction in the placebo group. } \\
\text { No significant difference between } \\
\text { the two groups was observed }\end{array}$ \\
\hline 5 & Vanelderen $^{27}$ & 2015 & $\begin{array}{l}\text { Lumbar } \\
\text { radicular } \\
\text { pain }\end{array}$ & $\mathrm{RCT}$ & $\begin{array}{l}\text { I7:17:17 } \\
\text { (minocycline: } \\
\text { amitriptyline: } \\
\text { placebo) }\end{array}$ & $\begin{array}{l}100 \text { mg once } \\
\text { daily }\end{array}$ & 2 weeks & $\begin{array}{l}\text { On NRS, I. } 47 \text { reduction in score in } \\
\text { the minocycline group vs } 1.4 \mathrm{I} \\
\text { reduction in the amitriptyline } \\
\text { group; only a small magnitude of } \\
\text { change was observed }\end{array}$ \\
\hline 6 & Syngle $e^{26}$ & 2014 & $\begin{array}{l}\text { Diabetic } \\
\text { neuropathy }\end{array}$ & $\mathrm{RCT}$ & $50(25: 25)$ & $\begin{array}{l}100 \text { mg twice } \\
\text { daily }\end{array}$ & 6 weeks & $\begin{array}{l}\text { On VAS, } 56.12 \% \text { reduction in the } \\
\text { score in the minocycline group vs } \\
17.32 \% \text { reduction in the placebo } \\
\text { group. On } \mathrm{BDI}, 53.98 \% \text { reduction in } \\
\text { score in the minocycline group vs } \\
23.94 \% \text { reduction in the placebo } \\
\text { group }\end{array}$ \\
\hline 7 & Narang ${ }^{23}$ & 2016 & $\begin{array}{l}\text { Leprotic } \\
\text { neuropathy }\end{array}$ & $\begin{array}{l}\text { Prospective } \\
\text { observational } \\
\text { study }\end{array}$ & 11 & $\begin{array}{l}100 \text { mg once } \\
\text { daily }\end{array}$ & 3 months & $\begin{array}{l}\text { Nine out of II patients: } \\
\text { improvement in motor function. Six } \\
\text { patients with neuritis: more than } \\
75 \% \text { reduction on the VAS score }\end{array}$ \\
\hline 8 & Curtin $^{21}$ & 2017 & $\begin{array}{l}\text { Carpal } \\
\text { tunnel } \\
\text { syndrome }\end{array}$ & $\mathrm{RCT}$ & $84(43: 40)$ & $\begin{array}{l}100 \text { mg twice } \\
\text { daily }\end{array}$ & 5 days & $\begin{array}{l}\text { Time to pain resolution was not } \\
\text { shortened after minocycline } \\
\text { administration }\end{array}$ \\
\hline 9 & Sumitani ${ }^{25}$ & 2016 & $\begin{array}{l}\text { Various } \\
\text { disorders }\end{array}$ & $\begin{array}{l}\text { Prospective } \\
\text { observational } \\
\text { study }\end{array}$ & 20 & $\begin{array}{l}100 \mathrm{mg} \\
(\mathrm{I} \text { week), } \\
200 \mathrm{mg}(3 \\
\text { weeks) }\end{array}$ & 4 weeks & $\begin{array}{l}\text { NRS }(5.6 \rightarrow 5.3, \text { no significant } \\
\text { reduction) }\end{array}$ \\
\hline
\end{tabular}

Abbreviations: CIN, chemotherapy-induced neuropathy; RCT, randomized controlled trial; MDASI, MD Anderson symptom inventory; NRS, numeric rating scale; VAS, visual analog scale; BDI, Beck depression Inventory. 
patients) over 4 months from the initiation of chemotherapy. The degrees of fatigue and neuropathic pain, and the levels of serum inflammatory markers, including IL receptors, tumor necrosis factor- $\alpha$ receptor, and C-reactive protein, were not significantly different between the two groups.

Martinez et $\mathrm{al}^{22}$ performed an RCT on lumbar radicular pain. Minocycline (100 mg twice daily) was administered to patients scheduled to undergo lumbar discectomy. Forty-three patients received minocycline for 8 days from the evening before surgery, and 42 patients received a placebo. At 3 months after the surgery, the severity of lumbar radicular pain between the two groups was not different. Vanelderen et $\mathrm{al}^{27}$ performed an RCT involving patients with subacute lumbar radicular pain owing to disc herniation, spinal stenosis, and failed back surgery syndrome. For 2 weeks, either minocycline (100 mg), amitriptyline $(25 \mathrm{mg})$, or placebo were administered, and 17 patients in each group completed the study. After 14 days, patients who had taken the minocycline and amitriptyline reported a reduction of 1.47 and 1.41, respectively, in the score on the numeric rating scale. Although the score on the numeric rating scale was significantly reduced compared with that in the placebo group, the magnitude of the reduction was small. The authors concluded that "the effect of minocycline in reducing lumbar radicular pain was not likely to be clinically meaningful."

The effect of minocycline on diabetic neuropathy was evaluated by Syngle et al. ${ }^{26}$ Fifty patients with diabetic neuropathy were equally allocated to either the minocycline or placebo group. The scores on the visual analogue scale were reduced considerably after using minocycline (100 mg twice daily) for 6 weeks compared with those with the placebo (minocycline: $6.7 \rightarrow 2.9$, placebo: $5.6 \rightarrow$ 4.6). The symptoms related to diabetic neuropathy were measured using the Leeds Assessment of Neuropathic Symptoms and Signs Pain Scale and the Pain Disability Index, both of which were significantly reduced in the minocycline group.

Narang et $\mathrm{al}^{23}$ conducted a prospective pilot study to evaluate whether minocycline could improve the symptoms of leprotic neuropathy. They administered minocycline $(100 \mathrm{mg})$ daily to 11 patients for 3 months and found that all six patients with neuritis showed a reduction in pain with a more than a $75 \%$ reduction in the score on the visual analogue scale at 3 months after the initiation of minocycline administration. Additionally, functional improvement was seen in 9 of 11 patients.
Curtin et $\mathrm{al}^{21}$ evaluated whether perioperative administration of minocycline would help reduce the time to pain resolution after carpal tunnel release. Minocycline (200 mg) or placebo was administered to patients with carpal tunnel syndrome (43 patients in the minocycline group, 40 patients in the placebo group) $2 \mathrm{~h}$ before the operation, and then $100 \mathrm{mg}$ of minocycline or placebo twice a day for 5 days. They reported that the perioperative administration of minocycline did not reduce the time to pain resolution (minocycline group: 3 weeks vs placebo group: 2 weeks).

Sumitani et $\mathrm{al}^{25}$ prospectively recruited 20 patients with neuropathic pain of various etiologies. They administered $100 \mathrm{mg}$ minocycline daily for 1 week and then $200 \mathrm{mg}$ daily for 3 weeks. At 4 weeks of therapy, the mean score on the numeric rating scale changed from 5.6 at baseline to 5.3; however, the degree of reduction was not significant. The limitation of this study was that the authors did not state what disorders caused the neuropathic pain.

No significant side effects were reported in any of the included studies.

\section{Discussion}

We reviewed nine studies that examined the effect of minocycline on neuropathic pain. Among these, four studies reported a positive pain-reduction effect.

Two of the three studies on chemotherapy-induced neuropathic pain showed a pain-reducing effect. Minocycline was also effective in controlling pain in diabetic and leprotic neuropathies. However, minocycline was not effective in controlling lumbar radicular pain and pain resolution after carpal tunnel release. Lumbar radicular pain is induced by a herniated lumbar disc or spinal stenosis, indicating that pain is in part attributable to nerve-root compression. The pain mechanism of carpal tunnel syndrome also involves the compression of the median nerve beneath the transverse carpal ligament. Based on the results of the reviewed studies, we speculate that when patients' disorders include a component of nerve compression, the effect of minocycline may not be sufficient to control neuropathic pain. In contrast, chemotherapy-induced, diabetic, and leprotic neuropathies have no component of mechanical nerve compression, and the causes of neuropathic pain are largely owing to nerve inflammation. ${ }^{30-32}$ In particular, in the leprotic neuropathy study, all patients with neuritis showed excellent outcomes in pain reduction after administration of minocycline. ${ }^{23}$ We believe that minocycline affects the inflammatory 
factor in neuropathic pain. The anti-inflammatory effect of minocycline is related to its ability to inhibit the activation of microglia, thereby reducing the production of proinflammatory cytokines. ${ }^{11-13,15}$ Because microglia in the spinal dorsal horn contribute to the persistence of neuropathic pain by releasing several cytokines that mediate pain signaling, downregulation of microglia by minocycline may alleviate neuropathic pain. ${ }^{33}$

Regarding the side effects of minocycline, although no significant adverse effects were observed in any of the included studies, various side effects, such as dizziness, fatigue, headache, and tooth discoloration toxicities, are known to occur after the use of minocycline. ${ }^{24}$ Therefore, clinicians or researchers should be aware of the potential of the occurrence of side effects with minocycline and observe their development closely during use.

We found that only four studies showed a positive pain-reducing outcome of minocycline, whereas the other five studies did not show significant positive results. In addition, despite the positive pain-reduction effect of minocycline in some previous studies, a successful outcome in a Phase III RCT evaluating the effectiveness of minocycline for alleviating neuropathic pain has not yet been reported. Therefore, we cannot conclude that the effect of minocycline on reducing neuropathic pain is of general utility; however, it can be said that minocycline has the potential to reduce neuropathic pain. To clarify this issue, further high-quality studies need to be conducted to establish the effect of minocycline according to the type of neuropathic disorder. In addition, to clearly elucidate the pain-reducing effect of minocycline, studies with a large number of subjects should be conducted in the future.

\section{Funding}

This research was supported by the 2020 Joint Research Project of Institutes of Science and Technology.

\section{Disclosure}

The authors report no conflicts of interest for this work.

\section{References}

1. Chang MC. Conservative treatments frequently used for chronic pain patients in clinical practice: a literature review. Cureus. 2020;12(8): e9934.

2. Colloca L, Ludman T, Bouhassira D, et al. Neuropathic pain. Nat Rev Dis Primers. 2017;3:17002. doi:10.1038/nrdp.2017.2

3. Latremoliere A, Woolf CJ. Central sensitization: a generator of pain hypersensitivity by central neural plasticity. J Pain. 2009;10 (9):895-926. doi:10.1016/j.jpain.2009.06.012
4. Chang MC. Efficacy of pulsed radiofrequency stimulation in patients with peripheral neuropathic pain: a narrative review. Pain Physician. 2018;21(3):E225-E234. doi:10.36076/ppj.2018.3.E225

5. Jang SH, Chang MC. At least 5-year follow-up after transforaminal epidural steroid injection due to lumbar radicular pain caused by spinal stenosis. Pain Pract. 2020;20(7):748-751. doi:10.1111/ papr.12905

6. Yaksh TL, Woller SA, Ramachandran R, Sorkin LS. The search for novel analgesics: targets and mechanisms. F1000Prime Rep. 2015;7:56. doi:10.12703/P7-56

7. Jha MK, Jeon S, Suk K. Glia as a link between neuroinflammation and neuropathic pain. Immune Netw. 2012;12(2):41-47. doi:10.4110/ in.2012.12.2.41

8. Milligan ED, Watkins LR. Pathological and protective roles of glia in chronic pain. Nat Rev Neurosci. 2009;10(1):23-36. doi:10.1038/ nrn2533

9. Zhao H, Alam A, Chen Q, et al. The role of microglia in the pathobiology of neuropathic pain development: what do we know? Br J Anaesth. 2017;118(4):504-516. doi:10.1093/bja/aex006

10. Majidi J, Kosari-Nasab M, Salari AA. Developmental minocycline treatment reverses the effects of neonatal immune activation on anxiety- and depression-like behaviors, hippocampal inflammation, and HPA axis activity in adult mice. Brain Res Bull. 2016;120:1-13. doi:10.1016/j.brainresbull.2015.10.009

11. Ledeboer A, Sloane EM, Milligan ED, et al. Minocycline attenuates mechanical allodynia and proinflammatory cytokine expression in rat models of pain facilitation. Pain. 2005;115(1-2):71-83. doi:10.1016/ j.pain.2005.02.009

12. Shultz RB, Zhong Y. Minocycline targets multiple secondary injury mechanisms in traumatic spinal cord injury. Neural Regen Res. 2017;12(5):702-713. doi:10.4103/1673-5374.206633

13. Sun JS, Yang YJ, Zhang YZ, et al. Minocycline attenuates pain by inhibiting spinal microglia activation in diabetic rats. Mol Med Rep. 2015;12(2):2677-2682. doi:10.3892/mmr.2015.3735

14. Garrido-Mesa N, Zarzuelo A, Gálvez J. Minocycline: far beyond an antibiotic. Br J Pharmacol. 2013;169(2):337-352. doi:10.1111/bph. 12139

15. Guasti L, Richardson D, Jhaveri M, et al. Minocycline treatment inhibits microglial activation and alters spinal levels of endocannabinoids in a rat model of neuropathic pain. Mol Pain. 2009;5:35. doi:10.1186/1744-8069-5-35

16. Bastos LF, Godin AM, Zhang Y, et al. A minocycline derivative reduces nerve injury-induced allodynia, LPS-induced prostaglandin E2 microglial production and signaling via toll-like receptors 2 and 4 . Neurosci Lett. 2013;543:157-162. doi:10.1016/j.neulet.2013.03.014

17. Raghavendra V, Tanga F, DeLeo JA. Inhibition of microglial activation attenuates the development but not existing hypersensitivity in a rat model of neuropathy. $J$ Pharmacol Exp Ther. 2003;306 (2):624-630. doi:10.1124/jpet.103.052407

18. Wang LN, Yang JP, Zhan Y, et al. Minocycline-induced reduction of brain-derived neurotrophic factor expression in relation to cancer-induced bone pain in rats. $J$ Neurosci Res. 2012;90(3):672-681.

19. Kraus RL, Pasieczny R, Lariosa-Willingham K, et al. Antioxidant properties of minocycline: neuroprotection in an oxidative stress assay and direct radical-scavenging activity. J Neurochem. 2005;94 (3):819-827.

20. Lampl Y, Boaz M, Gilad R, et al. Minocycline treatment in acute stroke: an open-label, evaluator-blinded study. Neurology. 2007;69:1404-1410.

21. Curtin CM, Kenney D, Suarez P, et al. A double-blind placebo randomized controlled trial of minocycline to reduce pain after carpal tunnel and trigger finger release. J Hand Surg Am. 2017;42(3): $166-174$.

22. Martinez V, Szekely B, Lemarié J, et al. The efficacy of a glial inhibitor, minocycline, for preventing persistent pain after lumbar discectomy: a randomized, double-blind, controlled study. Pain. 2013;154(8):1197-1203. 
23. Narang T, Dogra S. Minocycline in leprosy patients with recent onset clinical nerve function impairment. Dermatol Ther. 2017;30(1):e12404.

24. Pachman DR, Dockter T, Zekan PJ, et al. A pilot study of minocycline for the prevention of paclitaxel-associated neuropathy: ACCRU study RU221408I. Support Care Cancer. 2017;25(11):3407-3416.

25. Sumitani M, Ueda H, Hozumi J, et al. Minocycline does not decrease intensity of neuropathic pain intensity, but does improve its affective dimension. $J$ Pain Palliat Care Pharmacother. 2016;30(1):31-35.

26. Syngle A, Verma I, Krishan P, Garg N, Syngle V. Minocycline improves peripheral and autonomic neuropathy in type 2 diabetes: MIND study. Neurol Sci. 2014;35(7):1067-1073.

27. Vanelderen P, Van Zundert J, Kozicz T, et al. Effect of minocycline on lumbar radicular neuropathic pain: a randomized, placebo-controlled, double-blind clinical trial with amitriptyline as a comparator. Anesthesiology. 2015;122(2):399-406.

28. Wang XS, Shi Q, Bhadkamkar NA, et al. Minocycline for symptom reduction during oxaliplatin-based chemotherapy for colorectal cancer: a Phase II randomized clinical trial. J Pain Symptom Manage. 2019;58(4):662-671.
29. Wang XS, Shi Q, Mendoza T, et al. Minocycline reduces chemoradiation-related symptom burden in patients with non-small cell lung cancer: a Phase 2 randomized trial. Int J Radiat Oncol Biol Phys. 2020;106(1):100-107.

30. Brandolini L, d'Angelo M, Antonosante A, Allegretti M, Cimini A. Chemokine signaling in chemotherapy-induced neuropathic pain. Int J Mol Sci. 2019;20(12):2904.

31. Lockwood DN, Saunderson PR. Nerve damage in leprosy: a continuing challenge to scientists, clinicians and service providers. Int Health. 2012;4(2):77-85.

32. Pop-Busui R, Ang L, Holmes C, Gallagher K, Feldman EL. Inflammation as a therapeutic target for diabetic neuropathies. Curr Diab Rep. 2016;16(3):29.

33. Cho HK, Kang JH, Kim SY, et al. Changes in neuroglial activity in multiple spinal segments after caudal epidural pulsed radiofrequency in a rat model of lumbar disc herniation. Pain Physician. 2016;19(8):E1197E1209.

\section{Publish your work in this journal}

The Journal of Pain Research is an international, peer reviewed, open access, online journal that welcomes laboratory and clinical findings in the fields of pain research and the prevention and management of pain. Original research, reviews, symposium reports, hypothesis formation and commentaries are all considered for publication. The manuscript management system is completely online and includes a very quick and fair peer-review system, which is all easy to use. Visit http:// www.dovepress.com/testimonials.php to read real quotes from published authors. 